working life in psychiatric units but also overt racism. As a German junior doctor working on a locked ward I encountered several times such actions and remarks as a manic male patient marching up and down the daytime area, hands lifted in Hitlergrüss style, shouting "Heil Hitler" when I entered the ward, to the amusement of patients present.

Another middle-aged patient refused to be treated by a "kraut" and called me names in German. This patient was also admitted in a manic phase. Both patients eventually recovered and I then engaged them in a discussion about their behaviour and that it had deeply offended me. Both men were sorry and apologised and I felt that this had been important for me as their therapist but also as a human being.

Less fortunate are nurses of black appearance who are often on the receiving end of racist remarks. Even though it is accepted that disturbed patients may lack judgement, their remarks still have an impact on health professionals as people which render them helpless and angry.

A policy taking account of that could act as symbolic 'self defence'.

BIRGIT BERG, formerly Registrar of Forensic Psychiatry, Horton Hospital, Epsom KT19 8PZ

\section{Psychiatric research opportunities in the USA}

Sir: The recent article by Ó Flaithbheartaigh ('How to Do a Research Fellowship in Psychiatry in the USA' Psychiatric Bulletin. January 1995, 19, 40-42) provided very useful information for psychiatrists contemplating such an experience. It is surprising, however, that two of the most useful additional sources of information were not mentioned in the article. The Fogarty International Center at the National Institutes of Health fosters international cooperation and consultation in biomedical and behavioural science. It provides support for fellowships, research conferences, seminars, and other international collaboration.

The Office of Research at the American Psychiatric Association is also a critical information source. Established to provide leadership and a locus for communication for the psychiatric research community in the US, the Office of Research maintains detailed information on research funding and training opportunities, and science policy issues in general. We publish a quarterly newsletter, Psychiatric Research Report, available free to APA members and, importantly, also produce a Directory of Research Fellowship Opportunities in Psychiatry.

HaRold Alan Pincus, American Psychiatric Association, $1400 \mathrm{~K}$ Street, NW, Washington, DC 20005, USA

\section{Dealing with addiction problems}

Sir: Jim Van Os and Jan Neelman (Psychiatric Bulletin, January 1995, 19, 1-3) stated that "France is the only country in the European Union where the law provides for the psychiatric detention of "alcoholics presumed dangerous" ("La Loi du 15 Avril 1954"). In fact psychiatrists in Ireland work under a 1945 Mental Treatment Act which allows the detention of a person who is an addict and is believed to require for recovery at least six months preventive and curative treatment. For the purpose of the Act, an addict is defined as a person who

(f) by reason of addiction to drugs or intoxicants is either dangerous to himself or herself or others or incapable of managing his or her affairs or of ordinary proper conduct, or

by reasons of his or her addiction to drugs, intoxicants or perverted conduct, is in serious danger of mental disorder.

In 1981 the Health (Mental Services) Act was passed by the Oireachtas (Irish Parliament). This Act has not been brought into force as developments in international law have overtaken it. I am delighted to add that a White Paper on Mental Health Legislation is due to be published by the Irish Department of Health. On 3 February 1995 the Irish Division of the Royal College of Psychiatrists held a meeting to discuss the imminent proposals in the White Paper. At that meeting the general consensus was that involuntary admission was not an appropriate way of dealing with addiction problems.

\footnotetext{
Mental Treatment Act 1945. Government Publications, Dublin 2.

Health (Mental Services) 1981. Government Publications, Dublin 2.

Green Paper on Mental Health 1992. Department of Health Government Publications, Dublin 2.
}

Verena Keane, St Brendan's Hospital, Dublin 7 